\title{
AVALIAÇÃO DO CICLO DE VIDA DA PRODUÇÃO DE PELOTAS DE MINÉRIO DE FERRO: ESTUDO DE CASO*
}

\author{
Giancarlo Alfonso Lovón Canchumani ${ }^{1}$ \\ Francisco Mariano da Rocha de Souza Lima² \\ Marcelo Guimarães Araujo ${ }^{3}$ \\ Thales Crivelli Nunes ${ }^{4}$
}

\section{Resumo}

A indústria da mineração do ferro brasileira ocupa posição relevante no cenário mundial, exportando para os principais mercados consumidores os produtos beneficiados. Esta indústria de beneficiamento tem consumo elevado de recursos e de energia, o que consequentemente gera grandes quantidades de emissões gasosas, líquidas e sólidas, contaminantes do meio ambiente. Nesse contexto o presente artigo tem por objetivo avaliar o ciclo de vida da produção de pelotas de minério de ferro, através da identificação dos impactos ambientais gerados nas etapas de lavra, beneficiamento, transporte e pelotização, com o intuito de dar subsídios a medidas mitigadoras. Foi realizado um estudo de caso em uma empresa de produção de pelotas de minério de ferro e utilizando a metodologia de Avaliação do Ciclo de Vida, baseado na norma ISO 14040. De acordo com os resultados obtidos os impactos ambientais mais importantes em relação ao ciclo de vida da produção de pelota, são referentes à categoria de depleção dos recursos minerais com $64,4 \%$ do total ponderado e a emissão de particulados no processo de lavra, que monta a $28,6 \%$ do mesmo total. Enquanto a fase com maior contribuição para o impacto total para a produção da pelota é a de beneficiamento.

Palavras-chave: Avaliação do ciclo de vida - ACV; Pelotização; Avaliação de impacto ambiental.

\section{LIFE CYCLE ASSESSMENT OF IRON ORE PELLETS PRODUCTION IN BRAZIL: A CASE STUDY}

\section{Abstract}

The brazilian iron mining industry occupies important position on the world production, exporting the processed iron ore products to the main consumer markets. The brazilian beneficiation plants have high consumption of resources and energy, which consequently generates large amounts of gaseous, liquid and solid emissions that are environmental contaminants. In this context, this article aims to assess the life cycle of the production of iron ore pellets, by identifying the environmental impacts on the mining steps, beneficiation, transportation and pelletization, in order to give subsidies to mitigation measures. A case study was undertaken in an iron ore pellet production company and using the methodology of Life Cycle Assessment, based on ISO 14040 standard. According to the results, the most important environmental impacts, in relation to the life cycle of the pellet, refer to the category of mineral resources depletion with $64.4 \%$ of the weighted total and particulate emissions in the mining process, which amounts to $28.6 \%$ of this total. Meanwhile the step with the highest contribution to the total impact for pellet production is the beneficiation.

Keywords: Life cycle assessment LCA; Iron ore pellets; Environmental impact assessment.

1 Planejamento Energético, D.Sc., Pesquisador, Centro de Tecnologia Mineral - CETEM, Rio de Janeiro, RJ, Brasil.

2 Engenharia Mineral, D.Sc., Chefe do Serviço de Novos Produtos Minerais, Centro de Tecnologia Mineral CETEM, Rio de Janeiro, RJ, Brasil.

3 Planejamento Energético, D.Sc., Pesquisador, Fio Cruz, Rio de Janeiro, RJ, Brasil.

4 Engenheiro Ecoeficiência,Samarco Mineração, Gerência Geral de Tecnologia e Ecoeficiência, Belo Horizonte, Minas Gerais, Brasil. 


\section{INTRODUÇÃO}

O setor de minério de ferro tem consumo elevado de recursos e energia, o que consequentemente gera grandes quantidades de emissões gasosas, líquidas e sólidas, contaminantes do meio ambiente. Por isso, é de grande importância fazer uma avaliação do setor no que se refere às questões ambientais, tornando-se necessário conhecer, quantificar e qualificar os recursos utilizados, os resíduos, bem como as emissões geradas.

Nesse contexto, destaca-se a importância de se realizar estudos de Avaliação do Ciclo de Vida (ACV). A ACV é um instrumento de avaliação do impacto ambiental e à saúde associado a um produto ou processo, que compreende etapas. Estas etapas vão desde a extração das matérias-primas, elementares da natureza, que entram no sistema produtivo (berço) até a disposição do produto final após uso (tumulo) [1].

A experiência internacional na realização de ACV da produção do minério de ferro é ainda pouco aprofundada. Em geral, a abordagem ao referido minério é realizada como insumo em estudos de ACV da produção de aço [2-4].

No estudo realizado por Burchart-Korol [4], o minério do ferro é identificado como um dos componentes da produção do aço que geram impactos ambientais mais relevantes na saúde humana e na qualidade do ar. Isso devido ao processo de sinterização de minério de ferro, que é o maior contribuinte para as emissões de poeira e gás. $O$ alto consumo de eletricidade do insumo também é ressaltado.

No trabalho de Yilmaz [5] que realizaram um ACV da indústria de fundição de ferro com o objetivo de encontrar as melhores tecnologias disponíveis para reduzir os impactos ambientais ao menor custo, não considerou na fronteira de seu estudo a produção e beneficiamento do minério de ferro.

Awuah-Offei e Adekpedjou [6] realizaram uma avaliação de vários estudos prévios sobre avaliação de ciclo de vida no setor mineiro e concluíram que a aplicação dessa ferramenta no setor era ainda limitada, além de terem identificado um número reduzido de pesquisas.

No que se refere especificamente à indústria de minério de ferro brasileira, ainda é necessário dispor de estudos e bancos de dados consolidados que representem a real dimensão dos impactos ambientais da cadeia produtiva [7].

Nesse sentido o presente artigo tem por objetivo avaliar o ciclo de vida da produção de pelotas de minério de ferro, através da identificação dos impactos ambientais gerados nas etapas de lavra, beneficiamento, transporte e pelotização, com o intuito de dar subsídios a medidas mitigadoras. Por meio de um estudo de caso em uma empresa de produção de pelotas de minério de ferro, utilizando como base os princípios da série de normas ISO 14040 e 14044.

\section{MATERIAIS E MÉTODOS}

A metodologia empregada foi a Avalição do Ciclo de Vida (ACV conforme as normas ISO 14040 e ISO 14044 [8,9]. Na continuação são apresentados a definição de escopo, modelagem do sistema, a método de avaliação de impacto ambiental utilizado. 


\subsection{Definição do Escopo}

Avaliar os impactos do ciclo de vida da empresa SAMARCO, associados às operações de lavra, seu beneficiamento e a produção de pelotas (pellets) de minério de ferro. A partir do modelo de pesquisa proposto se delimitaram o escopo desta ACV conforme os resultados da visita técnica. Nesta etapa, alguns limites foram demarcados para obter um inventário que satisfizesse os requisitos de um estudo empírico.

A unidade funcional definida para o estudo é de 1 tonelada (uma tonelada) de pelotas (pellets) de minério entregues no navio no porto de UBU na SAMARCO em Anchieta/ES. A fronteira geográfica do estudo compreende o limite de bateria das instalações físicas da lavra e beneficiamento SAMARCO Unidade Germano em Mariana/MG, os minerodutos, unidade de pelotização SAMARCO Porto de Ubu em Anchieta/ES, até a entrega do produto ao navio. A fronteira temporal compreende de ao ano de 2013. Serão considerando as possíveis oscilações sazonais. Trata-se de um ACV do berço ao portão "cradletogate".

\subsection{Modelagem do Sistema}

Considera-se como fluxos auxiliares todas as entradas de matéria e energia, do meio ambiente para o sistema de produto, e que não fazem parte do fluxo do produto principal, ou seja, não presentes no produto final.

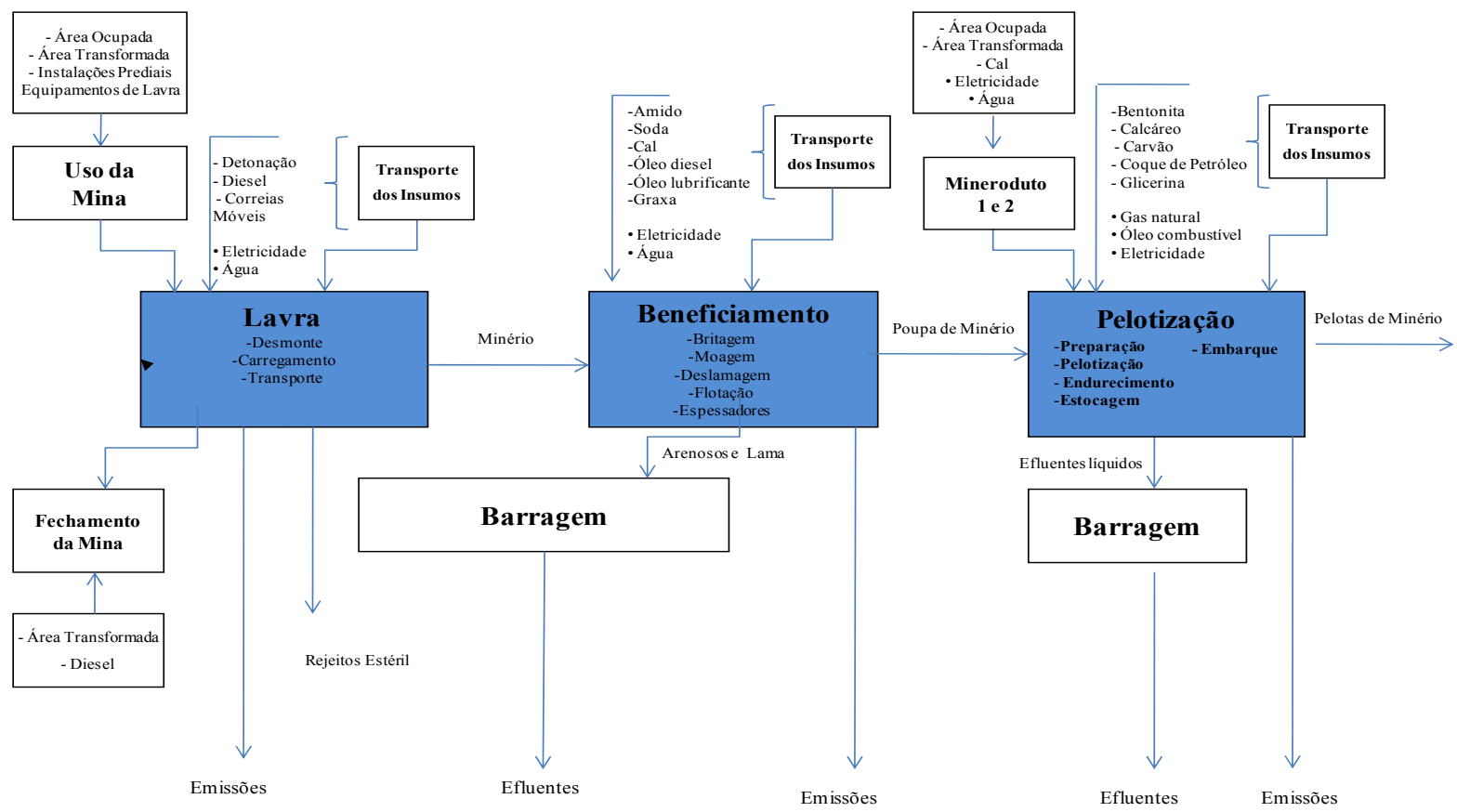

Figura 1. Modelagem do sistema de produção pelota de minério de ferro

A Figura 1 apresenta uma representação esquemática da modelagem do sistema de produção de pelotas de minério de ferro, seus fluxos intermediários (minério de ferro, concentrado de minério, pelotas de minério), seus fluxos auxiliares (amido, soda e cal, entre outros), e as saídas de emissões atmosféricas, efluentes líquidos e resíduos sólidos.

$\mathrm{Na}$ modelagem, criaram-se três subsistemas: Lavra ; Beneficiamento do minério bruto até a concentração desejada, incluindo a área de infraestrutura da empresa e 
a barragem de rejeito; e a Pelotização, no qual ocorre a produção da pelota de ferro em fornos, incluindo, mineroduto, instalações da fabrica e barragem de rejeitos.

Os dados primários analisados foram coletados em vistas técnicas, a empresa em estudo, para se obter as entradas e saídas no processo de pelotização de minério. Os dados secundários fortam tratados por meio de um software, o SimaPro 8.02. O software possui uma biblioteca de inventários e metodologias para avaliar o impacto de um produto em seu ciclo de vida [10].

\subsection{Método de Avaliação de Impactos do Ciclo de Vida}

A metodologia que será aplicada neste trabalho será a ReCiPe desenvolvida por RIVM,Radboud University, CML e Pré Consultants, 2008 [10]. Na Tabela 1 apresentam-se as categorias de impacto consideradas para a avaliação:

Tabela 1. Categorias de impactos consideradas para análise

\begin{tabular}{c}
\hline Categorias de Impacto \\
\hline Mudanças Climáticas \\
\hline Depleção de Ozônio \\
\hline Toxicidade Humana \\
\hline Formação fotoquímica \\
\hline Material Particulado \\
\hline Radiação lonizante \\
\hline Mud Climáticas Ecossistemas \\
\hline Acidificação Terrestre \\
\hline Eutrofização Agua \\
\hline Ecotoxicidade Terrestre \\
\hline Ecotoxicidade Água \\
\hline Ecotoxicidade Marinha \\
\hline Ocupação da Terra Agrícola \\
\hline Ocupação da Terra Urbana \\
\hline Transformação da Terra Natural \\
\hline Depleção de Recurso Minerais \\
\hline Depleção Fóssil
\end{tabular}

\section{RESULTADOS E DISCUSSÃO}

Os resultados da AICV da pelota de ferro Samarco pela metodologia ReCiPeEndpoint World podem ser analisados na Tabela 2. Nessa tabela pode-se observar que o processo com maior contribuição para o impacto total da pelota é o processo de beneficiamento do minério.

O processo de pelotização do minério beneficiado é relevante nas categorias de impacto ambiental de formação fotoquímica, acidificação terrestre e ocupação da terra urbana. Já o consumo de óleo combustível é relevante para a depleção de ozônio.

As outras fontes energéticas tem relevância para as categorias de mudanças climáticas radiação ionizante, ecotoxicidade terrestre para a eletricidade utilizada na pelotização e depleção fóssil e ecotoxicidade marinha para o gás natural. Já o carvão utilizado no processo gera impactos na depleção de fósseis e eutrofização da água. 
Tabela 2. Resultados da AICV da pelota de ferro Samarco por processos pela metodologia ReCiPeEndpoint World

\begin{tabular}{|c|c|c|c|c|c|c|c|c|c|}
\hline $\begin{array}{l}\text { Categoria de } \\
\text { Impacto }\end{array}$ & Unidade & $\begin{array}{l}\text { Benefici } \\
\text { amento* }\end{array}$ & $\begin{array}{l}\text { Pelotiz } \\
\text { ação** }\end{array}$ & $\begin{array}{l}\text { Bentonit } \\
\text { a }\end{array}$ & Óleo & Carvão & Eletricidade & $\begin{array}{c}\text { Gas } \\
\text { Natural }\end{array}$ & Outros \\
\hline $\begin{array}{l}\text { Mudanças } \\
\text { Climáticas }\end{array}$ & DALY & $41 \%$ & $0 \%$ & $4 \%$ & $2 \%$ & $12 \%$ & $18 \%$ & $6 \%$ & $17 \%$ \\
\hline $\begin{array}{c}\text { Depleção de } \\
\text { Ozônio }\end{array}$ & DALY & $6 \%$ & $0 \%$ & $5 \%$ & $70 \%$ & $1 \%$ & $2 \%$ & $4 \%$ & $13 \%$ \\
\hline $\begin{array}{l}\text { Toxicidade } \\
\text { Humana }\end{array}$ & DALY & $54 \%$ & $0 \%$ & $18 \%$ & $2 \%$ & $3 \%$ & $10 \%$ & $2 \%$ & $11 \%$ \\
\hline $\begin{array}{c}\begin{array}{c}\text { Formação } \\
\text { fotoquímica }\end{array} \\
\end{array}$ & DALY & $19 \%$ & $62 \%$ & $1 \%$ & $2 \%$ & $2 \%$ & $2 \%$ & $3 \%$ & $8 \%$ \\
\hline $\begin{array}{c}\text { Material } \\
\text { Particulado }\end{array}$ & DALY & $94 \%$ & $4 \%$ & $0 \%$ & $0 \%$ & $0 \%$ & $0 \%$ & $0 \%$ & $1 \%$ \\
\hline Radiação lonizante & DALY & $35 \%$ & $0 \%$ & $7 \%$ & $3 \%$ & $6 \%$ & $22 \%$ & $7 \%$ & $19 \%$ \\
\hline $\begin{array}{c}\text { Mudanças } \\
\text { Climaticas } \\
\text { Ecosistemas } \\
\end{array}$ & species.yr & $41 \%$ & $0 \%$ & $4 \%$ & $2 \%$ & $12 \%$ & $18 \%$ & $6 \%$ & $18 \%$ \\
\hline $\begin{array}{c}\text { Acidificação } \\
\text { Terrestre }\end{array}$ & species.yr & $17 \%$ & $58 \%$ & $2 \%$ & $1 \%$ & $4 \%$ & $3 \%$ & $8 \%$ & $8 \%$ \\
\hline Eutrofização Agua & species.yr & $18 \%$ & $0 \%$ & $5 \%$ & $0 \%$ & $62 \%$ & $8 \%$ & $1 \%$ & $5 \%$ \\
\hline $\begin{array}{c}\text { Ecotoxicidade } \\
\text { Terrestre }\end{array}$ & species.yr & $55 \%$ & $0 \%$ & $2 \%$ & $0 \%$ & $0 \%$ & $33 \%$ & $0 \%$ & $9 \%$ \\
\hline $\begin{array}{c}\text { Ecotoxicidade } \\
\text { Água }\end{array}$ & species.yr & $58 \%$ & $0 \%$ & $5 \%$ & $0 \%$ & $1 \%$ & $13 \%$ & $4 \%$ & $17 \%$ \\
\hline $\begin{array}{c}\text { Ecotoxicidade } \\
\text { Marinha }\end{array}$ & species.yr & $36 \%$ & $0 \%$ & $10 \%$ & $1 \%$ & $2 \%$ & $7 \%$ & $23 \%$ & $20 \%$ \\
\hline $\begin{array}{c}\text { Ocupação da Terra } \\
\text { Agrícola }\end{array}$ & species.yr & $81 \%$ & $0 \%$ & $1 \%$ & $0 \%$ & $3 \%$ & $11 \%$ & $0 \%$ & $3 \%$ \\
\hline $\begin{array}{c}\text { Ocupação da Terra } \\
\text { Urbana }\end{array}$ & species.yr & $36 \%$ & $42 \%$ & $2 \%$ & $0 \%$ & $13 \%$ & $1 \%$ & $0 \%$ & $7 \%$ \\
\hline $\begin{array}{c}\text { Transformação da } \\
\text { Terra Natural }\end{array}$ & species.yr & $26 \%$ & $14 \%$ & $23 \%$ & $0 \%$ & $4 \%$ & $18 \%$ & $6 \%$ & $8 \%$ \\
\hline $\begin{array}{c}\text { Depleção de } \\
\text { Recurso minerais }\end{array}$ & $\$$ & $100 \%$ & $0 \%$ & $0 \%$ & $0 \%$ & $0 \%$ & $0 \%$ & $0 \%$ & $0 \%$ \\
\hline Depleção Fóssil & $\$$ & $14 \%$ & $0 \%$ & $3 \%$ & $5 \%$ & $24 \%$ & $4 \%$ & $39 \%$ & $11 \%$ \\
\hline
\end{tabular}

*Intervenções ambientais do próprio processo de Pelotização não oriundas de outros processos, e.g. emissões do forno de pelotização, e outros.

Entretanto, é necessária a aplicação de uma metodologia para se avaliarem quais desses processos são os mais impactantes. Para tal, é necessária a normalização e a ponderação para converter os impactos em uma mesma unidade comparável. Assim consegue-se responder as perguntas se "Isso é muito?", e se "Isso é importante?" em referências aos valores de cada categoria de impacto. Os resultados de impacto ambiental ponderados para a pelota de ferro Samarco pela metodologia ReCiPeEndpoint World H podem ser visto na Tabela 3.

Tabela 3: Resultados dos impactos ambientais ponderados para a pelota de ferro Samarco pela metodologia ReCiPeEndpoint World $\mathrm{H}$.

\begin{tabular}{lcc} 
Categoria de danos & \multicolumn{2}{c}{ Impacto (Pt) } \\
\hline Saúde Humana & 22,50 & $30,9 \%$ \\
Ecossistemas & 0,22 & $0,3 \%$ \\
Recursos & 50,20 & $68,8 \%$ \\
\hline Total (Pt) & $\mathbf{7 2 , 9 2}$ & $\mathbf{1 0 0 , 0 \%}$ \\
\hline
\end{tabular}

Pode-se observar que a categoria de danos predominante é a de recursos, seguida de saúde humana e, finalmente, da categoria de danos ao ecossistema. Dos 50,2 Pts da categoria recursos 49,92 Pts são referentes à fase de beneficiamento. $O$ resultado do impacto ambiental ponderado para o processo de beneficiamento é 
apresentado na Tabela. Nela, se observa que o uso de recursos continua sendo a categoria de danos preponderante.

Tabela 4. Resultados dos impactos ambientais ponderados para os subsistemas Beneficiamento pela metodologia ReCiPeEndpoint World $\mathrm{H}$.

\begin{tabular}{lrr}
\hline Categoria de danos & \multicolumn{2}{c}{ Impacto (Pt) } \\
\hline Saúde Humana & 21,48 & $30,0 \%$ \\
\hline Ecossistemas & 0,11 & $0,1 \%$ \\
\hline Recursos & 49,92 & $69,8 \%$ \\
\hline Total & $\mathbf{7 1 , 5 1}$ & $\mathbf{1 0 0 , 0 \%}$ \\
\hline
\end{tabular}

Da mesma forma, pode ser observado os impactos ambientais ponderado para a fase de Lavra, que antecede a fase do Beneficiamento, na Tabela 5 A categoria de uso de recursos continua sendo a preponderante.

Tabela 5: Resultados dos impactos ambientais ponderados do subsistema Lavra pela metodologia ReCiPeEndpoint World $\mathrm{H}$.

\begin{tabular}{lrr}
\hline Categoria de danos & \multicolumn{2}{c}{ Impacto (Pt) } \\
\hline Saúde Humana & 11,30 & $29,5 \%$ \\
\hline Ecosistemas & 0,01 & $0,0 \%$ \\
\hline Recursos & 26,94 & $70,4 \%$ \\
\hline Total & $\mathbf{3 8 , 2 5}$ & $\mathbf{1 0 0 , 0 \%}$ \\
\hline
\end{tabular}

Assim denota-se que a categoria de danos mais importante é a de consumo de recursos nas três fases do ciclo produtivo da pelota de ferro Samarco e que é referente ao consumo de recursos na fase de Lavra.

A acumulação dos impactos ambientais ao longo das fases para cada uma das categorias de impacto ambiental da metodologia ReCiPeEndpoint pode ser vista na Figura 2. Os impactos são comparados com os valores finais totais das categorias para a pelota, considerada como $100 \%$. Assim, observa-se que, em geral, os impactos da última fase a Pelotização são maiores do que das fases anteriores, exceção para a categoria de impacto de material particulado na qual não há emissões modeladas para as fases de Pelotização e a categoria de depleção de recursos minerais.

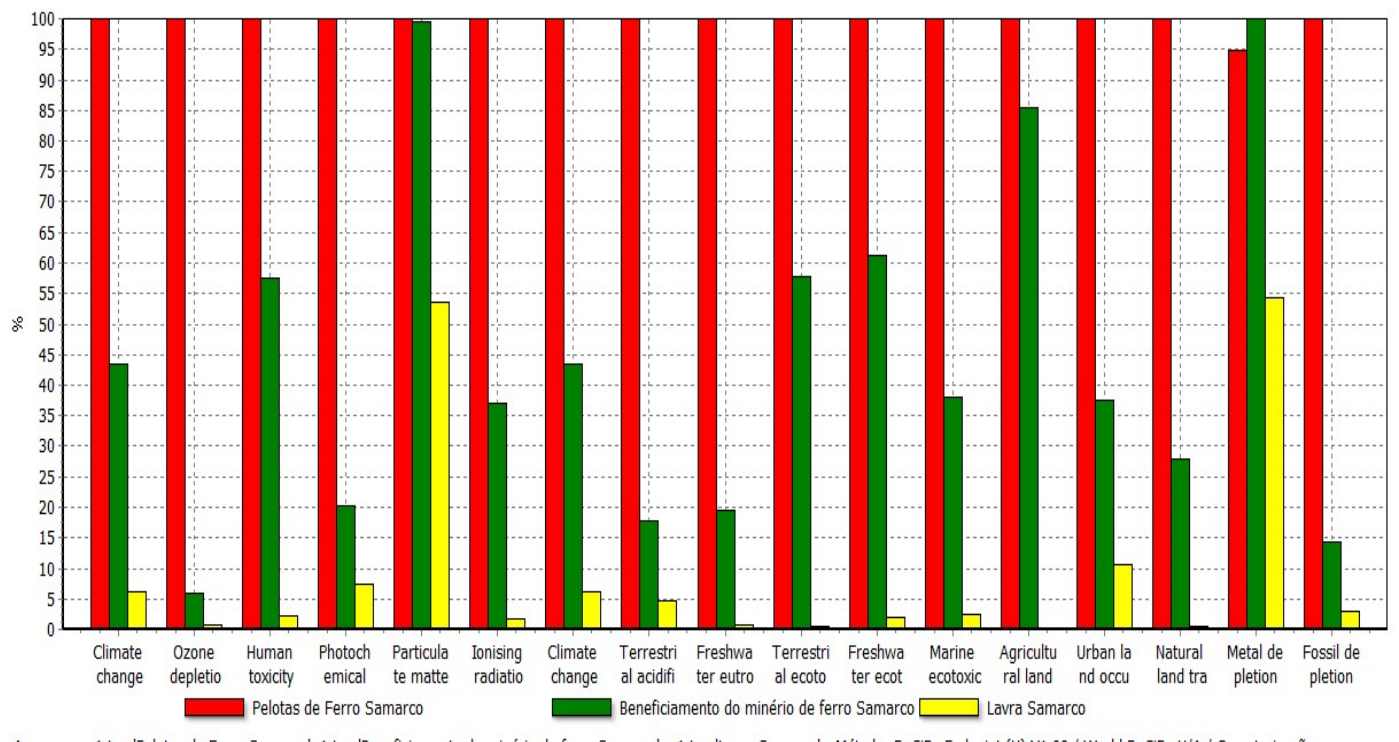

Figura 2: Resultado dos impactos ambientais para as fases de Lavra, Beneficiamento e Pelotização pelo método ReCiPeEndpoint. 


\subsection{Análise de Contribuição}

$\mathrm{Na}$ análise de contribuição se busca identificar quais são os processos mais impactantes em relação ao total dos impactos do ciclo de vida de um produto. Com isso é possível tomar ações para a redução dos impactos. A Figura 3 apresenta um gráfico de barras para as categorias de impactos ambientais da fase de pelotização para a pelota Samarco, utilizando-se a metodologia ReCiPeEndpoint.

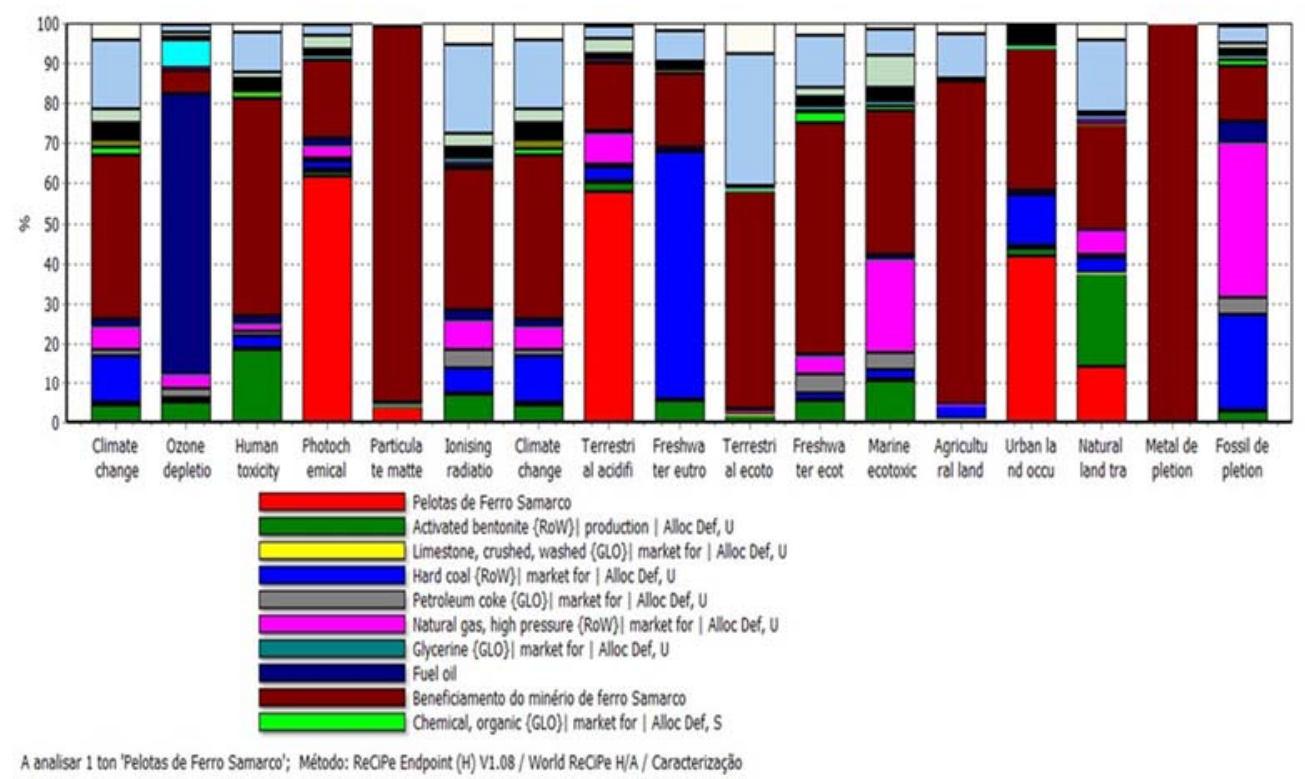

Figura 3. Impactos ambientais para 1 tonelada de pelota de ferro pela metodologia ReCiPeEndpoint

A Figura 3 mostra que a cor predominante é a marrom que representa percentualmente os impactos ambientais do processo de beneficiamento que antecede a pelotização. Em seguida destaca-se a cor vermelha referente ao processo de pelotização que gera impactos importantes para as categorias de fotoquímicos, uso da terra e acidificação terrestre.

\subsection{Comparação com Outros Estudos}

A Figura 4 abaixo apresenta o resultado da Avaliação de Impacto de Ciclo de Vida AICV da pelota Samarco comparada, utilizando a metodologia ReCiPeEndPoint., com a pelota de minério de ferro modelada no banco de dados Ecoinvent Iron pellet/Produção/GLO. O sistema de produto de referência para comparação, corresponde a um modelo de produção global.

$\mathrm{Na}$ figura 4 pode-se denotar que a pelota de ferro modelada no Ecoinvent tem impactos superiores à pelota Samarco em várias categorias de impacto, exceto ecotoxicidade terrestre e uso da terra agrícola. Sendo que são praticamente iguais para a categoria de impacto de depleção de recursos minerais, visto que o percentual de ferro na pelota final é o mesmo nos dois modelos.

Algumas categorias de impacto ambiental como mudanças climáticas, depleção de combustíveis fósseis e de ozônio tem explicações simples e diretas, visto que ocorre maior intensidade de hidroeletricidade no Brasil do que na média mundial da eletricidade modelada no Ecoinvent, gerando o Brasil uma energia elétrica mais limpa que causa menos impactos em várias categorias mais principalmente em mudanças climáticas, depleção de combustíveis fósseis e outras. 


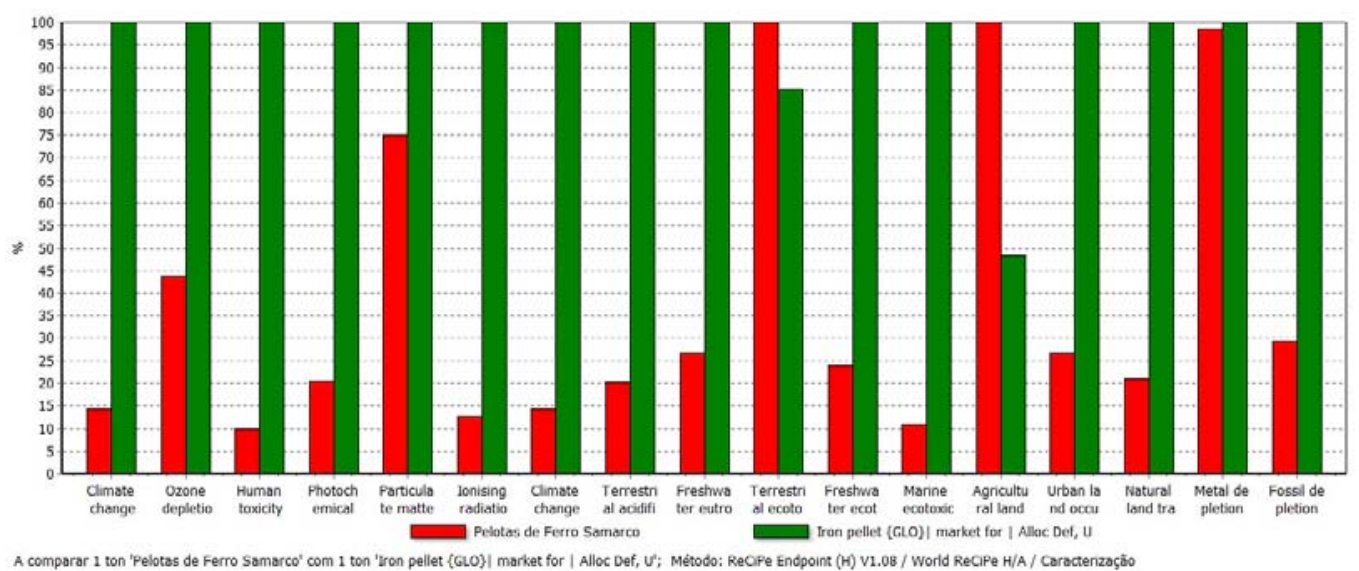

Figura 4: Resultado do AICV da pelota Samarco em comparação com a pelota do Ecoinvent pela metodologia ReCiPeEnd Point

O uso da terra é bem inferior na modelagem Samarco devido à recuperação de $80 \%$ da área da mina, a qual não é considerada na modelagem do Ecoinvent. Já para o uso de terra agrícola, ocorre um impacto devido às áreas necessárias para a produção de amido de milho e mandioca especificadas na modelagem da pelota Samarco, mas que não estão modelados no Ecoinvent, ou não são usados generalizadamente no dataset do Ecoinvent

Em suma, conforme a Tabela 6 pelo método ReCiPe World H/A os resultados ponderados do AICV indicam que a pelota Samarco tem impactos ambientais de $78 \%$ em comparação ao Ecoinvent.

Tabela 6. Comparação da pelota da Samarco com o Ecoinvent pela metodologia $\mathrm{ReCiPe}$

\begin{tabular}{cccc}
\hline $\begin{array}{c}\text { Categoria de } \\
\text { danos }\end{array}$ & $\begin{array}{c}\text { Pelotas de Ferro } \\
\text { Samarco }\end{array}$ & Iron pellet Ecoinvent & $\begin{array}{c}\% \\
\text { Samarco/Ecoinvent }\end{array}$ \\
\hline Saúde Humana & 22,5 & 35,9 & $63 \%$ \\
Ecossistemas & 0,2 & 0,9 & $24 \%$ \\
Recursos & 50,2 & 56,3 & $89 \%$ \\
\hline Total & $\mathbf{7 2 , 9}$ & $\mathbf{9 3 , 1}$ & $\mathbf{7 8 \%}$ \\
\hline
\end{tabular}

\section{CONCLUSÃO}

A Metodologia de ACV está sendo cada vez mais incorporados aos processos de decisão em empresas. Ela tem revelado sua importância na quantificação de impactos ambientais e na avaliação das melhorias do ciclo de vida de processo, produtos e atividades.

A aplicação da ACV para avaliação de impactos ambientais associados à mineração esta dentro de um movimento que ocorre não só no Brasil. Gradativamente as empresas compreendem que esta ferramenta permite o acesso a mercados mais sofisticados que certificam os processos produtivos das commodities e melhoram o acesso a uma base de dados para realização dos inventários da mineração. Diante das diferenças entre os tipos de exploração (a céu aberto ou open pit mining, e subterrânea ou underground mining), dos diferentes métodos de mineração e do volume limitado de estudos de cada unidade de processo (perfuração, detonação, escavação, transporte, esmagamento, triagem, etc.), as informações públicas disponíveis do processo de mineração não são conclusivas, pois são generalizadas, considerando um padrão médio de mineração [7]. 
Os resultados encontrados, no estudo de caso, demonstram que os impactos ambientais mais relevantes no tocante ao ciclo de vida da pelota, da extração de recursos naturais até a saída da fábrica (cradletogate), são referentes à depleção do minério de recursos minerais $(64,4 \%$ do total ponderado) e a emissão de particulados no processo de Lavra, que monta a $28,6 \%$ do total do impacto ponderado. Sendo o restante devido à vários processos entre os quais a queima do diesel nas máquinas da mina e o uso da terra.

Denote-se ainda que as resultados ambientais na produção da pelota de ferro, sejam emissões ou uso de insumos, não são todos totalmente relativas a empresa em estudo mas sim, são o somatório de todas as emissões de todos os processos da cadeia do ciclo de vida da produção da pelota. Portanto, não ocorrem necessariamente no mesmo sítio, tampouco no mesmo tempo, mas sim ao longo do ciclo de vida dos vários produtos e processos do sistema de produção da pelota de ferro.

A comparação com o estudo da produção de pelotas de ferro do Ecoinvent apresenta que a pelota SAMARCO tem impactos ambientais inferiores a do Ecoinvent. Entre outros motivos cabe ressaltar o uso da eletricidade de grid brasileiro reduzindo o impacto ambiental pelo uso de correias transportadoras dentro da mina e do mineroduto para o transporte ao invés de caminhões movidos a diesel. Não há, entretanto, nenhuma categoria de impacto apresentando resultados díspares.

\section{REFERÊNCIAS}

1 Guinée J.B., Heijungs H, Huppes G, Zamagni A, Masoni P, Buonamici, R. Life Cycle Assessment: Past, Present, and Future. Environmental Science and Technology. 2012: 45(1) 90-96, 2011.

2 Markus Engineering Services. Cradle-to-gate life cycle inventory: Canadian and US steel production by Mill Type.The Athena Sustainable Materials Institute, 2002.

3 Chen B,Yang JX, Ouyang ZY. Life Cycle Assessment of Internal Recycling Options of Steel Slag in Chinese Iron and Steel Industry. Journalof Iron and Steel Research, International. 2001;18(7): 33-40.

4 Burchart-Korol D. Life cycle assessment of steel production in Poland: a case study. Journal of Cleaner Production. 2013;(54): 235-243.

5 Yilmaz O, Anctil A, \& Karanfil T. LCA as a decision support tool for evaluation of best available techniques (BATs) for cleaner production of iron casting. Journal of Cleaner Production. 2014;(2): 1-11.

6 Awuah-Offei K, \& Adekpedjou A, Application of life cycle assessment in the mining industry.Int J Life Cycle Assess. 2011;(16):82-89.

7 Lima F, Canchumani G, Araujo M, Veiga L, Tardelli E, Ninô P. et. al.Avaliação do ciclo de vida - ACV da produção de minério de ferro, considerando os aspectos energéticos e ambientais. Relatório Técnico. Rio de Janeiro: CETEM, 2015.

8 ABNT. Associação Brasileira de Normas Técnicas. NBR ISO 14040: Gestão Ambiental - Avaliação do ciclo de vida - Princípios e estrutura. ABNT, Rio de Janeiro, 2009a.

9 ABNT. Associação Brasileira de Normas Técnicas. NBR ISO 14044: Gestão Ambiental - Avaliação do ciclo de vida - Requisitos e orientações. ABNT, Rio de Janeiro, 2009b.

10 Goedkoop M, Heijungs R, De Schryver A, Struijs J, Van Zelm R, ReCiPe 2008: A life cycle impact assessment method which comprises harmonized category indicators at the midpoint and the endpoint level / Report I: Characterization. Holanda. Ministerie van VROM, Den Haag, 2009. 